\title{
Pentecostes: o Espirito na formação das primeiras comunidades
}

Recebido: 18/07/2016. Aprovado: 30/08/2016.

\author{
Clélia Peretti* \\ Franciscarlo de Souza**
}

Resumo: O presente artigo analisa a presença e ação do Espírito Santo na formação das primeiras comunidades cristãs, com base nos escritos lucanos e paulinos. Esta ação é marcadamente presente na Sagrada Escritura. No Antigo Testamento é a Lei que direciona os passos do povo. No Novo Testamento o Espírito Santo não substitui a Lei, mas desenvolve o que o próprio Cristo disse: "não vim abolir a Lei ou os Profetas, mas dar-lhes pleno cumprimento" (Mt 5,17). Nas comunidades lucanas, o Pentecostes é o dado originário da Igreja: todos ficaram repletos do Espirito Santo. Nos escritos paulinos é o Espírito Santo que faz da Igreja o templo do Deus vivo e a comunidade dos concidadãos dos santos e membros da família divina. Se para Israel a fé é universal e inclusiva, para os cristãos, a lgreja é o novo Israel. Assim dá-se a continuação da obra de Jesus Cristo. Portanto, o Espírito habita na Igreja e no coração dos fiéis. A acolhida pessoal do Espírito Santo é o marco do início da vida cristã para os convertidos. O Espírito de Deus é a fonte de unidade e ação que move as neocomunidades à vivência do Evangelho. Este é percebido pelas comunidades como a Shekinah. No Pentecostes, sua dimensão é ilimitada, ultrapassa os parâmetros da fé judaica, e por isso, as comunidades dão início ao despertar de sua nova identidade e à reconstrução da história da lgreja e da missão cristã na perspectiva do plano salvífico de Deus na história. Portanto a comunidade entende-se como ekklêsia, convocação, congregação no Espírito Santo. Por conseguinte, é divina, é comunidade reunida no Espírito.

Palavras-chave: Pneumatologia. Comunidade. Missão da Igreja.

Abstract: This article analyzes the presence and action of the Holy Spirit in the formation of the first Christian communities, with base on lucanians and pauline writings. This action is markedly present in Holy Scripture. In the Old Testament the law directs the steps of the people. In contrast the New Testament is the Holy Spirit that does not replace, but develops what Christ himself said: "I have not come to abolish the Law or the Prophets, but to Them full compliance (Mt 5,17)". In lucanians communities, Pentecost, is the Church original data, everyone got filled with the Holy Spirit. In the pauline writings is the Holy Spirit that makes the Church the Temple of the living God, and the community of the saints and members of divine family. Thus, if Israel takes faith as universal and inclusive, for Christians, the Church is the new Israel. So give up the continuation of the work of Jesus Christ. Thus, Spirit dwells in the Church and in the hearts of the faithful. The personal welcome of the Holy Spirit is the mark of the beginning of the Christian life to the converted. The Spirit of God is the source of unity and action that moves the neo-communities to the Gospel living. This is perceived by the communities as the Shekinah. In Pentecost its size is unlimited, it exceeds the parameters of the Jewish faith, and so communities initiate the awakening of his new identity and the reconstruction of church history and Christian mission in the salvific plan of God's perspective on history. So the community is understood as ekklesia, call, church in the Holy Spirit. Therefore, it is divine, it is the community gathered in the Spirit.

Keywords: Pneumatology. Community. Church's mission.

* Pós-doutorado e Doutorado em Teologia. Professora no Programa de Pós Graduação Mestrado e Doutorado em Teologia da Pontifícia Universidade Católica do Paraná - PUCPR.

** Mestrando em Teologia na PUCPR. Bacharel em Teologia e Licenciatura em Filosofia. 


\section{Introdução}

Ao findar-se a obra do Filho confiada pelo Pai, o Espírito foi enviado em Pentecostes como fonte de santificação da Igreja. Nesta perspectiva, há uma reflexão sobre a presença e ação do Espírito Santo na formação das primeiras comunidades cristãs.

A teologia cristã enfatiza a ação singular do Espírito na Igreja e no coração dos fiéis. Recebemos "o Espírito que vem de Deus", diz São Paulo, "a fim de que conheçamos os dons da graça de Deus" (1Cor 2,12). Além disso, por meio desse dom, somos guiados para compreender a verdade, porque "o Espírito tudo perscruta, até mesmo as profundezas de Deus" (1Cor 2,10).

Ele possui a missão de unificar as realidades humanas com as divinas. O Lógos e o Pneuma são as forças iluminadoras dos seres humanos, as únicas fontes de luz divina. Ele esteve presente na história humana, e continua iluminando povos e nações na busca da verdade. Desde as mais antigas compreensões eclesiológicas, o mistério da Igreja é associado à atuação do Espírito, doado pelo Pai e por Jesus Ressuscitado. Com isso as Sagradas Escrituras atestam sua força vivificadora na criação do mundo, na história do povo de Deus, principalmente agindo nos profetas e, admiravelmente, na vida de Jesus. Se no Antigo Testamento é a Lei que direciona os passos do povo, no Novo Testamento é o Espírito Santo a guiar o próprio Cristo "a não abolir a Lei ou os Profetas, mas dar-lhes pleno cumprimento" (Mt 5,17). É o Espírito que torna visível a missão de Jesus. Nisso a comunidade que vive sob a orientação do Espírito Santo é caracterizada por uma variedade de carisma, pois é o Espírito que é o dispensador dos diversos dons que enriquece a vida da comunidade cristã.

É o Espírito Santo que norteia a vida e a ação das primeiras comunidades, segundo a pneumatologia lucana e paulina. Nos Atos dos Apóstolos notar-se-á que o Pentecostes é o dado originário da Igreja, pois o fato de que os discípulos ficaram cheios do Espírito Santo (At 2,4) significa também batismo no Espírito (At 1,5; At 11,16), derramamento do Espírito e de seus carismas (At 2,17-18; At 10,45.47). Esses textos bíblicos apontam para a confirmação da Igreja inaugurada pela ação do Espírito, que dá força a Palavra (kerigma) com o seu dinamismo. Assim a comunidade cresce (conversões) em sua universalidade: a Igreja é descrita como o novo Israel. Nela se dá a continuação da obra de Jesus Cristo. 
A teologia paulina é eminentemente cristológica. Nessa perspectiva, Paulo vai denotar Espírito de Cristo aquilo que concerne ao que é o Espírito Santo na experiência paulina em si e em suas primeiras comunidades, orientando os dons para edificação da Igreja de Cristo.

Ao atentar-se sobre o Pneuma na concepção do apóstolo, não se deve confundir o Espírito divino com outras formas usadas pelo apóstolo, por exemplo: "espírito do mal" ou "espírito do mundo" (1Cor 2,12), o "espírito de escravidão" (Rm 8, 15), ou "o espírito de quem suscita heresia" $(1 \mathrm{Tm} 4,1)$. É de suma importância observar que as comunidades desenvolvem-se a partir das experiências pneumáticas (cf. 1Cor 12,3), como acontece na comunidade de Corinto, na catequese batismal sobre o corpo de Cristo e da habitação do Espírito na Igreja.

A acolhida pessoal do Espírito Santo é o marco do início da vida cristã para os convertidos. Ver-se-á que não é abordado diretamente o tema da personalidade do Espírito Santo. Assim o Espírito é tido como o elo de união para formar um só corpo, pois "somos templos do Espírito Santo" e esse fortalece aqueles que creem no anúncio da Boa Nova. Destarte, o Espírito de Deus é a fonte de unidade e ação que move as neocomunidades à vivência do Evangelho. Essas são ações realistas e o Espírito Santo é percebido, em meio ao povo, como a Shekinah.

\section{A Palavra anunciada, testemunhada e animada, em Pentecostes}

A Sagrada Escritura é fonte de sentido, comunicação viva, luz para os caminhos, significado para a vida, ponte para as realidades, experiências divinas. A Palavra de Deus é transmitida de geração em geração para que ela permaneça viva e eficaz em nosso meio. É pela Palavra que conhecemos Deus, pois habita entre nós (Jo 1). Manifesta-se não só por sua forma escrita, mas antes de tudo, testemunhada por aqueles e aquelas que foram os seus receptores (Gn 12-50; Ex 1-18; Eclo 44-50). E aqui, pelo testemunho, mantém-se a história através da oralidade. Todavia, as tradições orais são postas no papel a fim de que permaneça aquilo que foi anunciado e vivido. É no reinado de Salomão que surgem os primeiros escritos sobre a história do Povo de Deus e é edificado um templo, lugar simbólico entre Deus e o povo (1Rs 5-9).

Retomando a Escritura é importante ressaltar que as sagradas letras não só são inspiradas, como também inspiram, pois narram a 
manifestação de Deus no meio do povo iniciando pelos Patriarcas e Matriarcas: Abraão e Sara, Isaac e Rebeca, Jacó, Lia e Raquel (Gn 12-30). Estes caminham na esperança da realização da promessa que se torna, pela fé, graça sobre todo o povo. Depois, parte para a entrada do povo por meio de José no Egito (Ex 1,1-5). O povo multiplica-se, contudo, o faraó homem de coração duro arquiteta contra os hebreus para que não se tornem uma ameaça ao povo egípcio (Ex 1,7-14). Nesse contexto ocorre a libertação do povo por Moisés, que com dificuldade caminha rumo à Terra Prometida (Ex 3,1-15). E, aos poucos, vai se constituindo a história do Povo de Deus.

De um momento histórico a outro, observam-se as narrações que expressam as limitações que o próprio povo tinha perante a vontade de Deus, que não era muito bem compreendida. Daí, as lamúrias e as falhas desse povo, que erra, mas nunca se esquece do amor de Deus. Um dado importante é que o povo tem uma experiência com o Deus da vida e percebe que não pode caminhar sem ele. Portanto, ao se analisar a história do Povo de Deus, de maneira especial, iniciando-se na história de Israel, que essa é permeada pela ação de Deus, constituindo-se uma história de fé (cf. BRIGHT, 2004, p.47-51). Atrelada a essa ideia é preciso considerar que:

A dimensão da fé é universal, não restrita. Acreditamos que é restrita pela forte tradição judaica. Lembremos que Noé e Abraão não eram judeus. $E$ as alianças foram traçadas. O povo de Israel é nômade. Analisemos a geografia e percebamos onde eles passaram, incluirão pessoas a sua fé. Nisto consiste o universalismo da fé: ver a inclusão da fé a partir de Deus e não de Israel. O fato da escolha de Israel como povo de Deus não é exclusivista, mas sim, inclusivista, pois eles, como dito eram peregrinos, nômades. A questão de escolher um povo, não significa que excluiu todos os outros. Pois Israel incluiria na fé a todos os povos, 'venham a mim todos os povos e nações' (cf. Is 55,5) (MARÇANEIRO, 2016, Nota 1).

Partindo do dado de que a fé é alimentada pela Palavra, donde provém o testemunho, deve-se buscar compreender que a ação do Espírito Santo na vida humana acontece na medida em que o homem se aprofunda na Palavra, pois pela fé acontece uma entrega total a Deus. Portanto, a fé é a resposta humana a Deus que fala. A fé vem da pregação da Palavra $(\mathrm{Rm} 10,17)$. Desse modo, estabelece uma das principais relações do Espírito Santo para com o ser humano: a pregação (cf. VERBUM DOMINI, 2010, n.25). 
Na pregação, ou seja, no anúncio da Palavra manifesta-se a vivacidade daqueles que a ouvem $(\mathrm{Hb} 4,12)$, e a partir da escuta, dar-se-á a acolhida da Boa Nova. Assim inicia-se o processo querigmático, que visa fazer com que a fé seja "muito mais do que um conhecimento preciso: ela é opção existencial fundamental de aceitação, de adesão e de confiança" (cf. LIMA VAZ, 1973, p.43-45). É exatamente isso que pode ser verificado no relato de At 10,34-43:

Então Pedro tomou a palavra e disse: Em verdade, reconheço que Deus não faz distinção de pessoas, mas em toda nação lhe é agradável aquele que o temer e fizer o que é justo. Deus enviou a sua palavra aos filhos de Israel, anunciando-lhes a boa nova da paz, por meio de Jesus Cristo. Este éo Senhor de todos. Vós sabeis como tudo isso aconteceu na Judéia, depois de ter começado na Galiléia, após o batismo que João pregou. Vós sabeis como Deus ungiu a Jesus de Nazaré com o Espírito Santo e com o poder, como ele andou fazendo o bem e curando todos os oprimidos do demônio, porque Deus estava com ele. E nós somos testemunhas de tudo o que fez na terra dos judeus e em Jerusalém. Eles o mataram, suspendendo-o num madeiro. Mas Deus o ressuscitou ao terceiro dia e permitiu que aparecesse, não a todo o povo, mas às testemunhas que Deus havia predestinado, a nós que comemos e bebemos com ele, depois que ressuscitou. Ele nos mandou pregar ao povo e testemunhar que é ele quem foi constituido por Deus juiz dos vivos e dos mortos. Dele todos os profetas dão testemunho, anunciando que todos os que nele creem recebem o perdão dos pecados por meio de seu nome.

A forma como a comunidade primitiva foi se estruturando se deu tão somente pela força, sopro vital do Espírito. Depois da Ressurreição o Pentecostes (At 2,1-37) foi um acontecimento de fundamental importância para o cristianismo. Nesse momento os primeiros cristãos receberam a força que encheu os seus corações e fez com que criassem coragem e pregassem a mensagem de Jesus. É perceptível que no Pentecostes sua dimensão é ilimitada, que ultrapassa os parâmetros da visão judaica, como nesta citação:

Estando Pedro ainda a falar, o Espírito Santo desceu sobre todos os que ouviam a pregação da Palavra. Os fiéis da circuncisão, que tinham vindo com Pedro, profundamente se admiraram, vendo que o dom do Espirito Santo era derramado também sobre os pagãos; pois eles os ouviam falar em outras línguas e glorificar a Deus. Então Pedro tomou a palavra: Porventura pode-se negar a água do batismo a estes que receberam o Espírito Santo como nós? E mandou que fossem batizados 
em nome de Jesus Cristo. Rogaram-lhe então que ficasse com eles por alguns dias (At 10,44-48).

Sucede uma mudança significativa do mundo cultural judeu para o cosmopolita grego, do rural para a realidade urbana, de comunidades ao redor da sinagoga para comunidades ao redor das casas nas periferias das grandes cidades. Personagens, como por exemplo Saulo de Tarso, tiveram que entrar num processo de conversão: passar do mundo da observância da lei que acusa e condena (judaísmo), para o mundo da gratuidade do amor de Deus que acolhe e perdoa (Rm 8,1-4.31-32; At 4,36-37).

Essas comunidades dão início ao despertar de sua nova identidade. O povo de Antioquia começou a perceber a diferença entre os judeus e os que acreditavam em Cristo e começaram a chamar os seguidores de Cristo de cristãos (At 11,26). A partir dessa classificação, a própria comunidade seguidora de Cristo cria a sua identidade. Todavia, são inúmeros os conflitos, a constituição da comunidade cristã não se estruturou de forma tranquila, como é comprovado no livro dos Atos dos Apóstolos. No meio desse enfrentamento, as pessoas amadurecem e fortalecem a fé.

\section{Atos dos Apóstolos: a edificação da Igreja no Espírito Santo}

A finalidade do livro do Atos dos Apóstolos possui algumas concepções diversas. Tem-se em vista que "os Atos dirigem-se, antes de tudo e diretamente, aos leitores cristãos provenientes do mundo pagão" (FABRIS, 1991, p. 26). Para Rinaldo FABRIS (1991, p. 24), o autor de Atos - Lucas - "pretende reconstruir a história da Igreja e da missão cristã para mostrar aos seus cristãos a realização do plano salvífico de Deus na história". Ainda, assevera o autor que "os Atos seriam uma apologia do cristianismo na tentativa de dar crédito à nova religião perante a autoridade romana, para obter os privilégios de 'religio licita', nos mesmos níveis do hebraísmo" (FABRIS, 1991, p. 24). Algo que ocasionou diversas e diferentes repercussões nas comunidades de discípulos.

É interessante observar, mesmo de modo simples, que a terminologia "ekklêsia ocorre 25 vezes nos Atos [...] designando a comunidade local ou territorial [...] e uma vez explicitamente no sentido de Igreja Universal (At 20,28)" (FABRIS, 1991, p. 218). Isso indica que os conflitos que a comunidade enfrenta são concretos, não só teóricos. A radicalidade e a verdade do evangelho estão em tensão com tudo aquilo 
que é contrário à vida. $\mathrm{O}$ evangelho sempre libertará a vida de tudo que a oprime. A Palavra também corrigirá certas incoerências na própria comunidade, como por exemplo, a visão errada sobre o Reino (At 1,6-8), a falta de confiança na comunidade (At 5, 39), a dicotomia entre o puro e o impuro (At 10, 15-11,9).

A Palavra pede a conversão, convoca para a mudança de atitudes e mentalidades. Mudança esta que se fortalecerá na medida em que a comunidade permite ser moldada pela ação do Espírito Santo. Portanto, para "conhecer a consciência eclesial dos primeiros crentes e o seu projeto ideal de comunidade é necessário examinar a [...] vida e a organização das primeiras comunidades" (FABRIS, 1991, p. 219).

Afirma-nos Fabris (1991, p. 78) que o livro dos Atos dos Apóstolos “pode ser chamado de o 'evangelho do Espírito'. A função e a ação do Espírito Santo em Atos emergem imediatamente através de um simples levantamento estatístico do vocabulário usado". Essa expressão, considerando as variações (Espírito, Espírito de Deus, Espírito de Jesus, entre outras), está presente na Bíblia de Jerusalém em 56 vezes.

A fórmula preferida por Lucas é com o artigo "o Espírito Santo" [...] to pneuma (to) hagion, que ocorre 21 vezes; em outros 16 casos, a expressão retorna sem artigo "Espírito Santo"; e 9 vezes encontra-se o uso de "o Espírito", to pneuma, sem adjetivo; em 3 casos o adjetivo é substituído por um genitivo como "(o) Espírito do Senhor" e por 2 vezes "o Espírito de Jesus". Sendo que ainda se destaca no contexto de Atos o Espírito Santo visto como a força, o sopro, o impulso do qual a comunidade necessita (5 vezes) (cf. FABRIS, 1991, p. 78).

De acordo com o texto grego original, nos Atos dos Apóstolos encontram-se quatro formas usadas pelo Espírito Santo para se referir a ele próprio: seu Poder - Espírito Santo; sua Personalidade - O Espírito; sua Santidade - O Espírito Santo; sua Personalidade e sua Santidade - O Espírito, o Santo (cf. FABRIS, 1991, p. 80-83).

No primeiro caso, tem-se o "Espírito Santo" (Pneuma Hagion), sendo que essa fórmula não é usada para a pessoa do Espírito Santo, mas o que Ele faz. A referência não é ao Doador, mas às suas dádivas e operações. No segundo caso, "o Espírito" (to Pneuma) indica a pessoa do Espírito Santo e não o seu caráter e os seus dons. No terceiro, tem-se "o Espírito Santo" (to Pneuma Hagion), onde aparece a ênfase no seu caráter de "Santo". E, por último, tem-se "o Espírito, o Santo" (to Pneu- 
$m a$, to Hagion), que enfatizam a sua personalidade e a sua santidade (cf. FABRIS, 1991, p. 79-83).

É o Espírito Santo o agente da experiência, sendo que ele atua na Igreja mobilizando uma renovação constante. E, na busca dessa renovação, a questão central é encontrar o kerigma no desenvolvimento da comunidade. Sem o Espírito Santo volta-se ao formalismo da velha aliança, ou seja, para um judaísmo tradicionalista. Nisto consiste a caminhada da comunidade cristã: atualizar sempre a Boa Nova no Espírito Santo.

Assim, a comunidade, diante de seus conceitos fundamentais, entender-se-á como ekklêsia, no sentido de convocação, congregação no Espírito Santo. Ou seja, a Igreja é uma convocação divina e uma comunidade de convocados, reunidos no Espírito. Ainda, a Igreja, aos poucos, compreender-se-á como sinal e instrumento da união com Deus e da unidade do gênero humano. Ela é uma realidade concreta do amor divino de Deus e, assim, é portadora da salvação.

\section{A construção da pneumatologia paulina na missão da lgreja}

É mister ter consciência de que "a teologia paulina é eminentemente cristológica" (GALVÃO, 2009, p. 53). No decorrer dos escritos paulinos pode-se perceber que sua cristologia "é soteriológica (refere-se à salvação) em torno do mistério pascal, que embarca a paixão, morte e ressurreição de Jesus" (GALVÃO, 2009, p. 53). É importante observar que o apóstolo Paulo "soube elaborar categorias de pensamento de grande expressividade e de profunda penetração da realidade cristã, como [...] sua pneumatologia ou definição teológica do Espírito Santo, que ele gosta de chamar "Espírito de Cristo"” (BARBAGLIO, 1989, p. 47, tomo I).

Assim, "o conceito paulino de Espírito tem três fontes principais: a revelação no cânon veterotestamentário, no judaísmo intertestamentário e no pensamento cristão primitivo. [...] Falar do Espírito é falar da presença e do poder de Deus" (PAIGE, 2008, p. 484). Além disso, "um fato óbvio, mas importante, é Paulo dar como certo que o Espírito Santo é Deus" (PAIGE, 2008, p. 485). É a partir disso que "o apóstolo busca orientar os dons pneumáticos para a edificação da ekklesia" (PESCE, 1996, p. 149). 
Entretanto, o conceito paulino de Espírito não é simplesmente uma continuação do ponto de vista veterotestamentário e judaico [...] [mas] explica-se a importância crescente do Espírito em Paulo com base na experiência que as comunidades cristãs primitivas tinham do Espírito em seu meio [...] na percepção da imanência de Deus durante o culto, na realização de milagres [...] e na inspiração na profecia, na experiência de coragem e sabedoria para anunciar o evangelho, mesmo em circunstâncias difíceis, e nos sentimentos de alegria (PAIGE, 2008, p. 485).

Entretanto, ao analisar nos escritos paulinos o termo Pneuma, é preciso ter consciência de que essa terminologia é importante. Ela nem sempre é aplicada de forma clara, mas de modo ambíguo, retratando ora o espírito humano, ora o Espírito divino (Espírito Santo).

O número de usos de pneuma significando espírito humano em Paulo é incerto, pois em muitas passagens não é claro se a referência é ao Espírito divino ou ao espírito humano. De qualquer modo, é significativo que o número de referências ao Espírito (Santo) supera em muito o das referências ao espírito (humano). A inferência imediata que se pode razoavelmente tirar é que para Paulo o evangelho não trata de espíritualidade inata esperando por libertação, mas do Espírito divino que age a partir de fora sobre a pessoa e nela (DUNN, 2008, p. 109-110).

Dessa maneira, pode-se perceber o Espírito ativo no seio da ekklêsia, quando Paulo deixa a comunidade fundada para se dedicar a outros objetivos. Sua atividade apostólica não termina, mas entra numa nova fase. A comunidade já possui uma vida própria, mas permanece sob sua responsabilidade (cf. PESCE, 1996, p. 119). Corinto é o exemplo de uma comunidade que se desenvolveu em experiências pneumáticas (cf. PESCE, 1996, p. 120). A seguir, apresentamos algumas características da pneumatologia paulina:

Primeiramente, em 1 Cor 12,3: "que ninguém, falando com o Espírito de Deus, diz: 'Anátema seja Jesus!', e ninguém pode dizer: 'Jesus é Senhor' a não ser no Espírito Santo”. Seria extensivo desenvolver a teologia presente nas entrelinhas deste versículo; todavia, mesmo não havendo clareza do que Paulo queria ao expressar tais palavras, é possível supor que esteja preocupado com a forma da conduta dos coríntios a respeito das ações pneumáticas, que poderiam ser semelhantes ao culto dos gentios (cf. PESCE, 1996, p. 123-126).

Em um segundo momento, temos em 1Cor 12,4-30 o discurso, amplo e orgânico, sobre os carismas, que são divididos em três partes: vv. 
4-11 formam a primeira parte, em que Paulo fala dos carismas; vv. 12-26 retratam os carismas na simbologia do corpo humano, para mostrar que mesmo sendo muitos e diferentes, compõem um só corpo; e vv. 27-30 referem-se à aplicação do símbolo do corpo à diversidade dos carismas (cf. PESCE, 1996, p. 127-128).

Um terceiro aspecto vê-se em 1Cor 12,31b-13,13, que apresenta um trecho de caráter didascálico. Não que seja em si doutrinal, mas é indicação de um caminho de vida cristã (cf. PESCE, 1996, p. 128). Ainda é notório que, em 1Cor 14,2-25, Paulo dá conselhos para que se desenvolva de maneira correta o modo de comportar-se diante dos dons pnematológicos, a fim de que não se extravie a mensagem de Cristo (cf. PESCE, 1996, p. 129-131). A ação da comunidade no Espírito é tida nos dois aspectos, grego (pneumai) e hebraico (ruah). Ambos têm uma denotação de hálito, o hálito da vida (cf. DUNN, 2008, p. 309).

Algo interessante a se observar na teologia paulina, no aspecto penumatológico, é que "as manifestações pneumáticas de Corinto não podem mais ser vistas como um fenômeno particular desta comunidade, mas se mostram como um fato típico das comunidades paulinas em geral" (PESCE, 1996, p. 131). Observe-se ainda que a catequese batismal de Paulo "tenha instruído os coríntios sobre o tema do corpo de Cristo e da habitação do Espírito na Igreja” (PESCE, 1996, p. 150).

Nota-se, na ação dos neocristãos, que nas primeiras comunidades fundadas por Paulo "o início da vida cristã dos seus convertidos [se dava] a partir do seu recebimento pessoal do Espírito" (DUNN, 2008, p. 472). E que "o dom do Espírito oferecia a força de motivação e de capacitação pela qual viveriam" (DUNN, 2008, p. 473). Tendo em vista, que todos poderiam receber o Espírito, desde que acolhessem a vivência da mensagem de Cristo, pode-se verificar em At 10,45: "o dom do Espírito Santo foi derramado também sobre os gentios". De fato o Espírito escatológico era derramado em todos e inteiramente sobre toda carne (cf. DUNN, 2008, p. 478). Como foi mencionado, "a ação do Espírito ao penetrar numa vida humana era aspecto demasiadamente fundamental da iniciação cristã" (DUNN, 2008, p. 478).

O Apóstolo Paulo não aborda de modo direto a questão da personalidade do Espírito Santo. Mas, às vezes, as expressões "o Espírito" e "Deus" se sobrepõem e têm funções aparentemente idênticas, que acabam por definir aspectos de quem é o Espírito Santo. Em outros momentos, ele distingue o Espírito de Deus e de Cristo ao ressaltar que ele "guia" 
os fiéis (G1 5,18; Rm 8,14), ou "revela" o mistério do Evangelho e suas implicações (1Cor 2,6-16; Ef 3,5), ou "ajuda" os fiéis na oração (Gl 4,6; Rm 8,15.26-27) (cf. PAIGE, 2008, p. 486). Contudo, o Apóstolo Paulo "com certeza não trabalha com definições de pessoas divinas como as que surgiram na teologia cristã mais tardia” (PAIGE, 2008, p. 486).

$\mathrm{O}$ apóstolo acumula imagens para as pessoas divinas. Fala do Espírito como "o 'sinal', a 'primeira prestação' - em outras palavras, o começo do processo da salvação" (DUNN, 2008, p. 480). Portanto, o Espírito é a marca que define o cristão (cf. DUNN, 2008, p. 483). É uma marca que, como se pode observar em Rm 2,29, "caracteriza o judeu como aquele que é circuncidado no coração, "no Espírito e não na letra'" (DUNN, 2008, p. 482). Nessa linha, na base de Rm 8,14 , em que "todos os que são conduzidos pelo Espírito de Deus são filhos de Deus", compreende-se que "o Espírito é o elo de união, é a participação comum no único Espírito que nos une como um só corpo" (DUNN, 2008, p. 485).

Enfim, a ideia de Espírito e de Espírito experimentado é algo fundamental para a espiritualidade paulina das primeiras comunidades ou igrejas, pois “a realidade existencial de 'receber o Espírito' era demasiadamente central para a sua concepção da transição crítica para o discipulado cristão" (DUNN, 2008, p. 495). É possível compreender e conceber o Espírito Santo como aquele que dá a vida e é manifestado na teologia pneumática paulina como "a força de Deus, capaz de comunicar a vida àqueles que creem" (FABRIS, 2001, p. 535). Nesse ponto de vista paulino, todos são "templos do Espírito Santo" (1Cor 6,19).

\section{Considerações finais}

Para as primeiras comunidades cristãs o Espírito Santo é presente e atuante, como também livre, em seu meio, não sendo concebido como dependente das necessidades ou orações dos fiéis. A existência da comunidade como assembleia dos crentes em Jesus Cristo, morto e ressuscitado, só é possível graças à ação do Espírito, que inaugura o tempo escatológico de plenificação da ação salvífica de Jesus, acessível universalmente. A comunidade é viva graças a essa ação fundamental do mesmo espírito que atuou em Jesus. A própria vinda e presença do Espírito Santo é o sinal do Cristo ressuscitado, pois ele prometeu que viria o Paráclito (Jo 14,16). E só se pode acolher a Deus e cumprir os seus desígnios, tendo antes uma experiência daquilo que ele é para o ser humano e todas as coisas 
criadas: o Deus que é presente e atuante. É um dom que se obtém pela fé que nasce na escuta, na abertura e na vivência da Palavra. É certo de que a fé cristã é uma realidade pós-pascal. E é o Espírito que torna público o acontecimento do mistério pascal. Paulo, de quem Lucas é discípulo, já intuía isto: "ninguém será capaz de dizer: 'Jesus é o Senhor', a não ser sobe influência do Espírito Santo" (1Cor 12,3).

Assim como o Espírito agiu na vida de Jesus e na vida das primeiras comunidades, continua agindo hoje na vida dos que se abrem à atuação da graça divida. É na fé em Jesus Cristo que a comunidade recebe seus carismas para, por meio deles, produzir frutos de vida nova. Porém, só o Espírito pode conceder carismas aos seres humanos, por si só a humanidade não os possui. E compreendendo, que em Deus há uma inclinação a querer e a fazer o bem a suas criaturas, a manifestação dos dons se realiza pelo Espírito Santo de forma gratuita, exigindo-se semente a adesão da fé. Assim, a terceira pessoa da Trindade é a presença constante de Deus em meio aos seres humanos. Portanto, é ele a Shekinah, ou seja, a presença de Deus, o seu modo de ser e de agir na criação. Como Israel não compreendia a pluralidade em Deus na unidade de pessoa, os israelitas associavam as ações apenas a Iahweh. Essa presença de Deus marcada pela Shekinah demonstra a ação íntima do Espírito de Deus no desenvolvimento da comunidade cristã.

É na convivência, na confraternização, na troca de experiências, nos momentos de oração de uns com os outros, nas visitas e nas relações interpessoais, que se fortalece o sentido de comunidade. Nesse sentido, no retorno às fontes das experiências cristãs, intuímos que a missão de Cristo se faz presente e atuante e é universalizada pelo Espírito. O Espírito Santo continua sua obra no mundo, mostrando-nos que estes também são os tempos do Espírito, pois a verdade plena só a encontra quem vive no seguimento de Jesus. O Espírito verdadeiro revela-se nesse processo de moldar a vida conforme o próprio Jesus.

A ação inspiradora do Espírito, porém, exige discernimento, para que o ser humano não se equivoque no caminho a seguir, pois as moções do Espírito acontecem no emaranhado da história. O Espírito está onde estão os seres humanos. Sua vivência ou sua ausência são percebidas nas decisões e nos atos humanos. Cabe acreditar que a sobrevivência das comunidades de fé, da humanidade e do planeta, dependerá do Espírito pelo qual os seres humanos se deixarem conduzir. Na história das relações de Deus com os povos, culturas e religiões, há sinais singulares da 
vitalidade e da presença da ação do Espírito. Este atua em nossa vida sem violência, respeitando nossa autonomia. Deste modo, promove e impulsiona e liberta, sem anular o esforço e a deliberação humana.

Portanto, a experiência com o Ressuscitado, proveniente do mesmo Espírito que inflamou o cristianismo nascente, não permanece limitada a cada indivíduo, mas se faz necessariamente comunitária, pois encontra na vida do Cristo Ressuscitado o núcleo de sua fé. É o Espírito Santo que comunica seus dons para a edificação da Igreja. O Espírito Santo "nos socorre em nossa fraqueza [...] e intercede por nós com gemidos inefáveis" (Rm 8,26). É mister observar que as comunidades de hoje se desenvolvem a partir das experiências pneumáticas (cf. 1Cor 12,3). Mas o caminho de abertura ao outro passa necessariamente por esse toque do Espírito. É esta atenção que se requer dos cristãos que buscam compreender o mundo de outras tradições religiosas. Fazer isso é não perder a possibilidade de captar os sinais dos tempos e os dons do Espírito. A ação do Espírito em curso nas religiões mostra que a promessa dele não pode ser totalizada por nenhuma religião, igreja e dogma; sua ação desveladora faz-se presente na criação, no caos social e nas feridas da humanidade.

\section{Referências}

BARBAGLIO, Giuseppe. As cartas de Paulo (II). São Paulo: Loyola, 1989 (Coleção Bíblica Loyola).

BENTO XVI. Verbum Domini, São Paulo: Paulinas, 2010.

BÍBLIA DE JERUSALÉM. 6. ed. São Paulo: Paulus, 2006.

BRIGHT, J. História de Israel. São Paulo: Paulus, 2004.

DUNN, James D. G. O dom do Espírito. In: A teologia do apóstolo Paulo. 2. ed. São Paulo: Paulus, 2008.

. O Espírito que dá a vida. In: A teologia do apóstolo Paulo. 2. ed. São Paulo: Paulus, 2008.

. Psyche e pneuma. In: A teologia do apóstolo Paulo. 2. ed. São Paulo: Paulus, 2008.

FABRIS, Reginaldo. A vida no Espírito. In: Paulo, apóstolo dos gentios. São Paulo: Paulinas, 2001. 
. Os Atos dos Apóstolos. São Paulo: Loyola, 1991 (Col. Bíblica Loyola 3).

GALVÃO, Carmen S. M. Ano Paulino: hino ao amor. In: O Recado, revista. Jan./Fev. 2009.

LIMA VAZ, Henrique. O Espírito Santo: pessoa, presença, atuação. São Paulo: Vozes, 1973.

MARÇANEIRO, Marcial. Ênfases teológicas. Curitiba, 2016. Notas de aula 1 - disciplina Temas de Pentecostalismo e Teologia Sistemática. Programa de Pós-Graduação stricto sensu em Teologia e Sociedade, Pontífica Universidade Católica do Paraná.

PAIGE. O Espírito Santo. In: HAWTHORNE, G. F.; MARTIN, R.P.; REID, D.G. Dicionário de Paulo e suas cartas. São Paulo: Loyola, Vida Nova, Paulus, 2008.

PESCE, Mauro. O crescimento pneumático nos crentes. In: As duas fases da pregação de Paulo. São Paulo: Loyola, 1996 (Coleção Bíblica Loyola 20).

E-mail dos Autores:

cpkperetti@gmail.com desouza.franciscarlo@gmail.com 